Perla and Marmorston-Gottesman.-Haemolysin formation and the suprarenal glands Jl. Exp.Med., May, 1928.

Pineles.-Wien. Med. Wochenschr., No. 44, 1925.

Pines.-Brit. Jl. of Ophthal., 1927 and 1929.

Plummer-Recent work on Vitamins. Practitioner, July, 1928.

Poulard.-Traité d'Ophtalmologie, 1923.

Price.-Textbook of medicine, 1926.

Putter.-Die Drei Drusenfh. Brit. Med. Jl., June, 1928.

Rauber-Kopsch.-Lehrbuch der Anatom., 19:0.

Richard and Roesh.- Internal secretions of the kidneys and its clinical applications. Revue française D'Endocrinol., December, 1924.

Rolleston, Sir Humphry.-The Harveian Oration on Cardio-viascular diseases. Brit. Med. Jl., October, 1928.

Schiff.-Fortshrif. der Med., No. 21, 1926.

Schlayer.-Münch. Med. Wochenschr., No. 20, 1926. Ibid., No. 23. 1926.

Ibid., No. 11, 13, 15, 1926.

Shaw, Batty.-Hyperpiesia and hyperpiesis. 1922.

Snapper.-The non-excretory functions of the kidneys. Brit. Med. Jl., May, 1928.

Spence.-Brit. Med. Jl., August, 1928

Stevens.-The practice of medicine. 1926.

Swanzy.-Handbook of the diseases of the eye. 1925.

Thomas and Ensley.-Minnesot. Med., May, 1928.

H. Tidy.-An index of symptomatology. 1928.

Vaughan.-Internat. Clinic, 1911.

Waldstein.-Zeitschr. Gynecol., 1927.

Parkes Weber.-Brit. Med Jl., February, 1928.

Williamson.-Transient hemiplegia. Jl. Med. Ass. of S. Africa, May, 1928.

Young.-Brit. Med. Jl., January, 1929.

Zuelzer.-Medic. Klinik, May, 1928.

\title{
INTRA-CAPSULAR CATARACT EXTRACTION AT MOGA, PUNJAB
}

BY

\author{
C. Conor O'Malley, B.Sc., M.B., D.O.M.S.
}

GALWAY

IN discussing ways and means of cataract extraction, there is a tendency, perhaps more marked in this country than abroad, to be slightly shocked at any apparently radical operative procedure. This is surely contrary to the spirit of modern surgical progress. Reasoning by analogy, we must congratulate throat surgery on the passing of the defunct tonsillotomy operation. The days of that futile operation are no more, when patients paid an annual visit to have another piece snipped off the tonsil. One makes a mental comparison of the convincing nature of an operation like excision of the gall-bladder, as against a mere drainage of its contents. Remembering that the cataractous lens is a degenerated if not 
diseased structure, one is inclined to think that its complete extraction is a more convincing surgical procedure than a mere expression of the contents of its capsule. In the following remarks on intra-capsular cataract extraction, I am concerned only with one method, based on the so-called " expression" operation. The term "expression" is, perhaps, not a happy one, as to the uninitiated it suggests force. One can point out at the same time that every form of capsulotomy operation involves " expression"; the expressive force used by any method is but an index of the operator's skill.

In September, 192\%, I visited Moga Clinic, by kind invitation of the Surgeon in charge, Dr. Mathra Das. It was the Autumn busy season, and during my stay over 1,200 cataract extractions, as well as other eye operations, were done. This part of India has been long identified with intra-capsular extraction. Not far away, at Amritzar, Mulroney introduced a method of intra-capsular extraction and later Colonel H. Smith established his famous clinic at Jullundur.

At Moga, for the past 25 years, Dr. Mathra Das has worked tirelessly, year after year, with scarcely a break. His total of cataract extractions at Moga alone, has now reached 105,000. During the cold, slack months at Moga, he visits various areas in the south to operate at the invitation of local philanthropists. In January this year, at Benares, he did 1,019 cataract extractions in four days. This type of nomadic eye clinic is a great boon to the Indian poor. The best known to Western readers is perhaps the celebrated clinic of Dr. Holland at Shikarpur. At Moga each year during the Spring and Autumn busy seasons, Dr. Mathra Das teaches the operation of intra-capsular extraction to upwards of 80 doctors from various parts of India and visitors like myself from overseas. Many of the visitors are beginners at cataract surgery, so that personal coaching in each detail of the operation entails a lot of patience on the part of Dr. Mathra Das-a patience that is remarkable in view of the enormous amount of work to be got through each day. I am mentioning these facts partly because I am indebted to Dr. Mathra Das for his hospitality, and also to dispel an erroneous view held by at least one writer, ${ }^{1}$ on intra-capsular extraction.

On seeing the intra-capsular operation in India for the first time, the thing that struck one in studying the extracted lenses was the number that were still transparent throughout the greater part of their extent. The particular patients concerned were already incapacitated and sought relief. One realized with capsulotomy one's inability to do anything for such patients for months, perhaps years. One came to the conclusion that complete extraction in one form or another must be the operation of the future.

Any form of cataract extraction is subject to a severe trial under 
the conditions that exist amongst hospital patients in India, with the exception, perhaps, of the better organized centres like Madras and Bombay. That intra-capsular extraction, as done by Dr. Mathra Das, has stood the test of time is evident from the increasing numbers at the clinic over a long period of years. A similar inference is drawn by Colonel Smith in reference to his own well-known pioneer work at Jullundur. It is to be regretted that circumstances in India do not permit of exact statistics of after-results amongst the village population. It is not unreasonable to suggest, however, that the villager, there, as elsewhere, arrives at his own conclusions in his own way about the merits or demerits of surgical operations.

The outstanding characteristic of Dr. Mathra Das' technique is its simplicity. He uses few instruments. He relies on his own dexterity, and the assistance of a skilful non-medical assistant-the latter an expert of 14 years standing. While discussing the Barraquer operation with Dr. Mathra Das, he pointed out that if his hand had sufficient skill to manipulate a complicated instrument like the erisifaco, he was more likely to be successful with a simple instrument like the modified squint-hook. In other words, success with any method depends on the operator's skill.

At Moga, all extractions, except in young people, are intracapsular, and every type of lens is extracted, lower pole first. The instruments are as those introduced by Colonel Smith for intra-capsular extraction by the upright method, and are so well known that it is unnecessary to detail them here. 'The method is described in Colonel Smith's book, ${ }^{2}$ under the heading of "New Indian operation." The routine operation at Moga differs in some respects from that description, some details of which I give below. For the moment I will mention that Mathra Das never uses a spatula for counterpressure as described by Smith, nor does he use an auxiliary instrument such as Fisher's needle. He keeps his left thumb over the eyebrow for control, but rarely uses it for counter pressure.

On consideration of the simple dynamics of the presenting lens, it is difficult to see the necessity for counter pressure. First, take soft cataract, counter-pressure is liable to rupture the capsule in the eye, and besides, in this type, the lower pole doubles up on itself and slips outside the cornea, without any tendency to shift at the upper pole. In hard cataract, if the lens hook is applied at the right point on the sclerotic, the lower pole comes up, as in soft lenses, and is delivered in the same way without any counterpressure above. If the upper pole tends to present, assuming the corneal section is correct, it means that the hook is not applied at the right point, namely, the posterior lip of the lower pole of the lens. 
At Moga, in the busy season, there is no time for elaborate or even simple tests of the conjunctival sac before operation. All patients, including eyes with raised tension, where there is any prospect of useful vision resulting, are operated on without delay. Acute trachoma cases get a short preliminary treatment with silver nitrate, which is used in strengths of up to 15 per cent. In short, unless there is gross lid disease present, each patient goes to operation on the day of arrival at the hospital. This means that a large number of cases with the milder lid infections and with various stages of trachoma or glaucoma, are operated on without any preparatory treatment. In any criticism of the results of operation, this should not be forgotten. I will give a brief description of the operation as done by Dr. Mathra Das. A spring speculum is inserted, the outer lashes trimmed with scissors and the conjunctival sac thoroughly flushed with a solution of $1-3000$ perchloride of mercury. A large corneal section is made with puncture just in the sclerotic and counter puncture exactly at the limbus at $180^{\circ}$. The section finishes above in clear cornea. A small iridectomy is done in all cases. The speculum is removed and a lid hook inserted by the assistant in such a way as to raise the upper lid, including the fornix, clear off the globe. The lower lid is controlled by the assistant's left fore-finger. 'The lid control takes all external pressure off the globe. Next comes lens delivery : with an uncanny accuracy, the result of endless practice, Mathra Das applies the lens hook at a certain point on the sclerotic, or on the cornea as the case may be, and lifts up the lower pole with a smooth, uniform movement, causing the cornea to fold up behind the posterior lens face till the latter drops quietly from its final attachment at the upper pole. Much care is given to replacing the iris, as this is the most likely source of trouble in this operation. Indeed, I may say that in the hands of Mathra Das, it is the only source of trouble worth considering. The lens being delivered, and the iris attended to, the operator takes control and closes the lids, applying a pad and bandage, or proceeds to operate on the second eye. Bandages are not disturbed for six days-when they are replaced by a green eye shade. If the wound does not show firm healing, the bandage is re-applied. Patients, on an average, leave hospital on the day following the removal of bandages, and only a small percentage return for refraction. In stating my personal experience of the operation, I will try and discuss the main difficulties. By the courtesy of Dr. Mathra Das, I performed a number of extractions by his method.

The Corneal Section.-There is nothing difficult in this. The main thing to remember is that the complete lens is large to the eye accustomed to the capsulotomy lens. A large section, at least $180^{\circ}$. is essential, and it must include the whole width of the cornea. For 
this reason, the knife enters on the sclerotic externally and comes out exactly at the limbus internally, so as to get the maximum width without cutting vascular conjunctiva. The section finishes above in the cornea. Generally speaking, the lower the corneal section, the easier it is to deliver the lens by this method. To one accustomed to peripheral sections, cutting through clear cornea tends to offend the aesthetic sense. The subsequent scar is, however, not unsightly, and in actual practice the objection is more apparent than real. There is no reason to believe that the field of vision is appreciably interfered with subsequently, by a low incision.

The Iridectomy.-At Moga an iridectomy is always done, and it extends as far peripherally, as possible. The idea is not concerned with the merits of iridectomy per se, but rather to avoid the danger of getting the lens impacted in an inelastic pupil. To make the subsequent iris reposition more easy and certain, my own impression is that an iridectomy should be omitted where possible, as suggested by Morton. ${ }^{3}$

Lens Delivery.-Lid control is perfect. The upper lid and superior fornix are lifted clear off the globe, and the lower lid gently drawn down with a finger. There is no external pressure on the globe. The critical point in delivering the lens is to have some estimate of its extent peripherally. As a result of observing the various types being extracted, one learns the point to look for the lower pole of the lens. In general, the softer the lens, the shorter its vertical diameter. Conversely, the harder the lens, the longer its vertical diameter. So one looks for the lower pole in soft lenses at the lower border of the cornea or limbus, and in hard lenses, at varying points below in the sclerotic. Locating the thin edge of a hard lens below the limbus may seem a difficult matter, which it is to the beginner. With the perfect lid control and the eyeball rolled up, a position it always seems to occupy, automatically relaxing the superior rectus, there is absolutely no tension on the globe contents. Under these conditions the sclerotic dimples behind the lower edge of the lens without any force being required.

Having once found the lower edge, the hook must not be again removed. Gentle pressure is applied along a line which is a tangent to the lower posterior face of the lens. The lower pole is felt to slip upwards. The hook point follows without any relaxing until the lower pole is seen to bulge the iris below, and you know that the lens is coming normally. The hook follows close over the limbus and on to the cornea. Having reached the cornea, the movement is maintained of a gentle steady pressure along a line tangent to the posterior surface of the lens at any given moment, with a deliberate side-to-side movement along the corneal fold which shuts off the vitreous and gently disengages the lateral edges 
of the lens. With these movements are combined a slight lifting movement, which keeps the lens well forward in the eye and so under control. For this reason also, the angle through which the lens is made to tilt, should be as small as possible. Once the movement of lens delivery is started, it must be continuous throughout, until the lens hangs free outside the cornea. Any relaxation tends to let the upper pole dip backwards and vitreous to present above when pressure is re-applied. This is the only cause of vitreous loss, in my experience, associated with the operation. It tends to happen only with the rigid lens, which by virtue of its rigidity tilts the upper pole backwards as its lower pole comes forward. If the support of the hook below is relaxed, the lens as a whole sinks deep in, with its lower edge tilting forward. Great care is then necessary to manipulate the cornea behind the posterior face of the lens and lift its upper pole back into position without rupturing the vitreous. With a little patience, however, this can always be done. The ideal to aim at, in delivery, having once got the lower pole to the level of the lower third of the cornea, is to keep it there without any further uptilting. The operator then proceeds to fold the cornea from below, upwards, up behind the posterior face of the lens. The folding cornea is kept in close apposition across its whole width, to the posterior face of the lens. If this position is maintained throughout, without any sudden relaxation, or sudden increase of pressure, vitreous will not and cannot escape.

In passing over the resistant limbus, contact of the lens is apt to be lost. There is also the possibility of getting the hook point entangled in a bead of conjunctiva which is pulled up or torn by the fixation forceps. To avoid this, fixation should be made to one side of the vertical meridian.

Replacing the Iris.-This, in my experience, is the most trying part of the whole operation. The iris is liable to get driven into corners by the large lens, and must be dislodged with scrupulous care. We are familiar, in doing capsulotomy, with the manner in which the weight of the lids and speculum causes the vitreous to come forward to replace the extracted lens. The effect, of course, is to remove any concavity of the cornea, and make the achievement of a symmetrical iris quite easy. In the intra-capsular operation, there is no pressure on the globe, consequently the cornea remains concave. It is therefore difficult to be certain if the iris is where it ought to be, as the cornea regains its convexity only after the lids are closed. In my opinion the cornea should be reposed so that the wound edges are in careful apposition: this would make iris reposition an easier matter. I have never seen any attempt to replace the cornea before closing the lids. One obvious way is to allow lid pressure on the globe, without removing lid control. This, however, means losing a big feature of the 
operation, namely, the complete absence of any external strain on the vitreous. Another way is to replace the cornea directly with an instrument suitably fashioned to raise the sunken cornea. This suggests a danger of injuring Descemet's membrane. The risk, however, cannot be serious, since comparatively bulky instruments like Kalt's forceps and Barraquer's erisifaco must, of necessity, ordinarily come in contact with the endothelial layer of the cornea without any reported untoward results. Personally, I think that the only weak feature in this whole operation is the iris difficulty, as the majority of cases of adherent iris and prolapse are cases that were not accurately reposed at operation. I have tried a preliminary iridectomy, but found that there were usually adhesions between iris and capsule. This tendency to posterior synechiae with any iris trauma, though apparently unfavourable for other reasons, is perhaps an important cause of less frequent prolapse with the capsulotomy operation.

I have appended a rough analysis of a series of 220 extractions I did at Moga. The figures help to show the incidence of accidents at the operation, and subsequently until closure of the wound :-

\begin{tabular}{|c|c|c|c|c|c|c|c|}
\hline \multicolumn{3}{|c|}{ Number of extractions 220} & \multicolumn{5}{|c|}{ Average age 55} \\
\hline \multicolumn{3}{|c|}{ Accidents at operations } & \multicolumn{5}{|c|}{ Complications found on removing bandages } \\
\hline $\begin{array}{c}\text { Capsule } \\
\text { burst }\end{array}$ & Vitreo & as loss & $\begin{array}{c}\text { Coloboma. } \\
\text { trical }\end{array}$ & $\begin{array}{c}\text { Small } \\
\text { prolapse }\end{array}$ & $\begin{array}{c}\text { Moderate } \\
\text { or large } \\
\text { prolapse }\end{array}$ & Sepsis & $\begin{array}{c}\text { Flap } \\
\text { everted }\end{array}$ \\
\hline 3 & 1 much & $\begin{array}{l}2 \text { small } \\
1 \text { doubt- } \\
\text { ful }\end{array}$ & 6 & 5 & 6 & 3 & 1 \\
\hline
\end{tabular}

Since leaving India my intra-capsular extractions are not sufficiently numerous on which to base any conclusion.

At first glance, the figures are not flattering. The only complication of consequence, however, is adherent iris or prolapse.

Dealing with accidents in order, I can say that burst capsule is a minor matter. In all three cases the capsule burst with the lens practically delivered, leaving the capsule attached above. This was easily removed with forceps. Vitreous loss is not startling. In the case where it was considerable, the loss occurred in the right eye owing to the patient squeezing under the pad, while the left was being operated on. A considerable number of these extractions were on both eyes at the same time. In the West we avoid doing both eyes at the same time, a risk it is not possible to avoid in India. 
Adherent iris, though undesirable, is, as pointed out by Dr. Holland, ${ }^{4}$ not inconsistent with good vision. An attempt was made in all cases to excise the prolapse even when small.

Sepsis.-This seems formidable. We have to consider that there was no pre-operation attempt to treat infected lids. This figure is therefore not surprising to anyone who understands the Spartan conditions in India. I may mention that sepsis was remarkably rare in the hands of Mathra Das. My own cases were probably predisposed by the unnecessary trauma of a beginner at the operation. The case of everted flap was probably in no way an accident peculiar to this operation.

Conclusions.-There is no reason why this operation should not become a success with European surgeons. It is difficult to conceive a better method under the severe tests of Indian conditions. Soft lenses are simple and in these cases we would like to avoid capsulotomy. The completely hard lens is often difficult, but in these cases capsulotomy is not so objectionable. With skill, practically every lens can be delivered in capsule without accident. When real difficulty arises, it generally means a faulty corneal section. The operator should not risk losing his temper wrestling with a rigid lens, but should do capsulotomy.

I do not see the necessity for counter-pressure in any case. With a skilled hand there are few lenses that cannot be delivered by the hook only. When it is necessary to call in counter-pressure, assuming the section is correct, it can only mean a dangerously tough suspensory ligament. In such a case I believe a capsulotome and not a spatula is indicated. Consider what happens if we persist and apply force above with a spatula, and below with a hook. Something must give suddenly. This happens. The lower pole shoots up with a rush and the operator is caught napping and has not time to fold the cornea behind the rising lens. The lens tilts right over. The upper pole slips back into the vitreous which escapes above it.

Knowing something of the prejudice against intra-capsular extraction as described by its great exponent Colonel Smith, it is with some hesitation I venture to speak of it.

I have seen Barraquer's operation done by a surgeon of standing, and saw more vitreous loss than with the Indian operation in relatively unskilled hands. We must admit, that as yet, there is no standard procedure in the capsulotomy methods that gives complete satisfaction. Some surgeons wash out soft lens matter, some condemn this manoeuvre. Many use atropine and hope for the best. Omitting needlings and their troubles altogether, opinion is still anxiously uncertain about capsulotomy methods of extraction. 
It follows that we are far from having devised a thoroughly satisfactory method of extra-capsular extraction. Under the circumstances, I think it not unreasonable here to draw attention to a sound method of intra-capsular extraction.

\section{REFERENCES}

1. Meding, C. B.-New intra-capsular operation. Arch. of Ophthal., Vol. I, p. $569,1929$.

2. Smith, Henry.-The treatment of cataract. 1928 Edition.

3. Morton, H. M.-Intra-capsular extraction without iridectomy. Amer. Jl. of Ophthal., S. 3, 12, 90-98, 1929.

4. Fisher, W. A. and Holland, H. T.-1,455 cataract operations, pp. 14-15.

\section{TWO CASES OF QUININE AMBLYOPIA WITH UNUSUAL OPHTHALMOSCOPIC PICTURE}

BY

Lt.-Col. J. N. Duggan, O.B.E., D.O.(Oxon.), F.C.P.S. AND

B. P. Nanavati, D.O.M.S., M.R.C.S.(Eng.), L.R.C.P.(Lond.)

Two cases of quinine amblyopia which came under our observation at the Sir C. J. Ophthalmic Hospital, Bombay, are reported below with a view to bring out prominently the unusual ophthalmoscopic picture in both of them, namely marked oedema of retinae with normal discs and retinal blood vessels, as contrasted with the usual classical fundal appearance of quinine amblyopia.

Case No. 1.-Miss M. R., a Goanese girl, aged 9 years, had an acute attack of malaria for which she was given two and a half grains of quinine sulphate four times a day at four-hourly intervals. The next day, on taking the second dose the patient suddenly went blind in both eyes, so the remaining doses were not given. She was given a smart saline purge by her family doctor who brought her to the Sir C. J. Ophthalmic Hospital on September 3, 1927, about 20 hours after the onset of blindness. On inquiry no history of headache, nausea or tinnitus aurium could be obtained.

Clinical Examination.-The little patient had a vacant look. The eyes were totally blind, there being absence of even perception of light. The pupils were widely dilated and immobile. Fundal examination of each eye showed an absolutely normal disc and retinal blood vessels, but there was oedema of the retina extending right to the periphery of the fundus which looked yellowish white in colour. A red spot, though not of bright red tint, marked the 